\title{
Factors determining the survival of nasopharyngeal carcinoma with lung metastasis alone: does combined modality treatment benefit?
}

\author{
Xun $\mathrm{CaO}^{1,2 \dagger}, \mathrm{Li}-\mathrm{Ru} \mathrm{He}^{1,3 \dagger}$, Fang-Yun Xie ${ }^{1,3}$, You-Fang Chen ${ }^{1,2}$ and Zhe-Sheng Wen ${ }^{1,2^{*}}$
}

\begin{abstract}
Background: Nasopharyngeal carcinoma (NPC) with lung metastasis alone has been reported as a relatively favorable prognostic group, and combined modality treatment might be indicated for selected cases. However, the prognostic factors determining survival of this group and the indication of combined therapy have not been thoroughly studied.

Methods: We retrospectively reviewed 246 patients of NPC with lung metastasis(es) alone presented at diagnosis or as the first failure after primary treatment from 1993 to 2008 in an academic tertiary hospital. Univariate and multivariate survival analyses of post-metastasis survival (PMS) and overall survival (OS) were carried out to determine the prognostic factors.
\end{abstract}

Results: The 3-year, 5-year, and 10-year of PMS and OS for the whole cohort were $34.3 \%, 17.0 \%, 8.6 \%$ and $67.8 \%$, 45.4\%, 18.5\%, respectively. The median PMS (45.6 months vs. 23.7 months) and OS (73.7 months vs. 46.2 months) of patients treated with combined therapy was significantly longer than that of those treated with chemotherapy alone $(P<0.001)$. Age, disease-free interval $(D F I)$ and treatment modality were evaluated as independent prognostic factors of OS, while only age and treatment modality retain their independent significance in PMS analysis. In stratified survival analysis, compared to chemotherapy alone, combined therapy could benefit the patients with $\mathrm{DFI}>1$ year, but not those with $\mathrm{DFI} \leq 1$ year.

Conclusions: Age $\leq 45$ years, DFI $>1$ year, and the combined therapy were good prognostic factors for NPC patients with lung metastasis(es) alone. The combination of local therapy and the basic chemotherapy should be considered for these patients with DFI > 1 year.

\section{Background}

Nasopharyngeal carcinoma (NPC) is most prevalent in southeastern Asia [1,2], the histology of which is almost World Health Organization (WHO) types III (undifferentiated) [3]. In contrast to other squamous cell carcinoma of the head and neck, NPC is characterized by a high tendency for metastatic dissemination [4,5]. About 5-8\% of NPC patients are present with distant metastasis(es) at diagnosis, and 30 to $60 \%$ of locally advanced patients will develop distant metastasis(es) and die of disseminated disease $[2,4,6]$. NPC with distant metastasis makes a very

\footnotetext{
* Correspondence: wenzhsh@sysucc.org.cn

† Contributed equally

'State Key Laboratory of Oncology in South China, Cancer Center, Sun YatSen University, Guangzhou, China

Full list of author information is available at the end of the article
}

heterogeneous group, of which the post-metastatic survival can vary considerably ranging from weeks to years [7-9].

The lung is a one of the most common organ to which distant metastasis can occur in NPC patients $[10,11]$. Hui et al reported that, compared with other metastatic patterns, those with lung metastasis(es) alone presented a significantly better overall survival [7]. Others have reported up to 60 months disease-free survival in patients with solitary intrathoracic metastasis treated aggressively with combined therapy $[8,12,13]$. Thus, we postulate that it may be associated with a unique biologic behavior in NPC patients with lung metastasis(es) alone. However, to our best knowledge, the mechanism behind the phenomenon and the precise predictive factors for intervention
C Biomed Central

(c) 2011 Cao et al; licensee BioMed Central Ltd. This is an Open Access article distributed under the terms of the Creative Commons Attribution License (http://creativecommons.org/licenses/by/2.0), which permits unrestricted use, distribution, and reproduction in any medium, provided the original work is properly cited. 
and prognosis of this group haven't been clearly identified.

To date, the role of chemotherapy is well established for metastatic NPC, but the objective response is still far from satisfied [14-19]. Although several publications have shown in small cohorts that NPC patients with lung metastasis(es) alone may benefit from combined therapy, no data exists in larger patient cohorts [8,20-22]. We set out this retrospective study thought to add more evidences to help define the predictive factors of this group in a large cohort, and to facilitate the selection of the appropriate group to receive combined modality treatment for a better survival.

\section{Methods}

\section{Patients}

A database was prospectively established for the purpose of this analysis. Between 1993 and 2008, a total of 246 NPC patients with lung metastasis(es) (either present at diagnosis or at the first failure after receiving primary treatment) in Sun Yat-Sen University Cancer Center were consecutively enrolled. All the patients were pathologically confirmed NPC, and evaluated as complete remission for local-regional disease after primary treatment of radiotherapy with or without chemotherapy. Lung metastasis(es) was routinely determined by chest $\mathrm{X}$-ray and/or computed tomography (CT). When both $\mathrm{X}$-ray and/or CT were insufficient to confirm lung metastasis(es), the pathological confirmation by biopsy was then carried out. Patients who have preexisting malignant disease or a second primary tumor, or those with extra-pulmonary metastases were excluded. The study was approved by the medical ethics committee of Sun Yat-Sen University Cancer Center.

The stages of the disease were classified according to the Tumor-Node-Metastasis system (NCCN 2007). The differentiation status and histotype of the disease were classified according to the World Health Organization (WHO) classification for NPC. The characteristics of the 246 NPC patients enrolled in the study are shown in Table 1.

\section{Treatments}

For patients presented with lung metastasis(es) at diagnosis (M1), 6 cycles of chemotherapy with Cisplatin/5-fluorouracil (PF) regimen were administered before concurrent chemoradiotherapy. The PF chemotherapy regimen consisted of 20 to $30 \mathrm{mg} / \mathrm{m}^{2}$ cisplatin intravenous bolus on days 1 to 3 and 800 to $1,000 \mathrm{mg} / \mathrm{m}^{2} / 24$ hours continuous intravenous infusion of 5 -fluorouracil on days 1 to 4 of each cycle, repeated every 21 days. For those with M0 stage, radical radiotherapy or concurrent chemoradiotherapy with the Cisplatin-based regimen were performed for early stage or locally advanced NPC patients, respectively. During the treatments, new metastatic lesions were found
Table 1 Characteristics of 246 NPC patients with lung metastasis(es) alone at diagnosis or the first failure

\begin{tabular}{|c|c|}
\hline Characteristics & No. of patients (\%) \\
\hline \multicolumn{2}{|l|}{ Age (years) ${ }^{a}$} \\
\hline$\leq 45$ & $130(52.8)$ \\
\hline$>45$ & $116(47.2)$ \\
\hline \multicolumn{2}{|l|}{ Gender } \\
\hline Male & $196(79.7)$ \\
\hline Female & $50(20.3)$ \\
\hline \multicolumn{2}{|l|}{ Histology } \\
\hline WHO type I & $3(1.2)$ \\
\hline WHO type II & $7(2.8)$ \\
\hline WHO type III & $236(96.0)$ \\
\hline \multicolumn{2}{|l|}{$E B V V C A-\lg A^{b}$} \\
\hline$\leq 320: 1^{c}$ & $100(40.7)$ \\
\hline > 320:1 & $70(28.5)$ \\
\hline \multicolumn{2}{|l|}{$E B V E A-\lg A^{b}$} \\
\hline$\leq 40: 1^{d}$ & $112(45.5)$ \\
\hline$>40: 1$ & $58(23.6)$ \\
\hline \multicolumn{2}{|c|}{ UICC T classification } \\
\hline $\mathrm{T} 1-2$ & $97(39.4)$ \\
\hline T3-4 & $149(60.6)$ \\
\hline \multicolumn{2}{|c|}{ UICC N classification } \\
\hline NO & $41(16.7)$ \\
\hline N1-3 & $205(83.3)$ \\
\hline \multicolumn{2}{|c|}{ UICC M classification } \\
\hline MO & $201(81.7)$ \\
\hline M1 & $45(18.3)$ \\
\hline \multicolumn{2}{|l|}{ Lung metastasis } \\
\hline \multicolumn{2}{|l|}{ DFI (years) } \\
\hline$\leq 1$ & $92(37.4)$ \\
\hline $1-3$ & $86(35.0)$ \\
\hline$>3$ & $68(27.6)$ \\
\hline \multicolumn{2}{|l|}{ Metastasis site } \\
\hline Unilateral & $118(48.0)$ \\
\hline Bilateral & $128(52.0)$ \\
\hline \multicolumn{2}{|l|}{ Metastasis number } \\
\hline Solitary & $82(33.3)$ \\
\hline Multiple & $164(66.7)$ \\
\hline \multicolumn{2}{|c|}{ Metastasis size $(\mathrm{cm})^{e}$} \\
\hline$\leq 2$ & $147(59.8)$ \\
\hline$>2$ & $99(40.2)$ \\
\hline
\end{tabular}

Abbreviation: NPC, nasopharyngeal carcinoma; WHO, World Health Organization; UICC, International Union Against Cancer; DFI, disease-free interval.

${ }^{a}$ Median age;

${ }^{b}$ Data was available for 170 cases:

${ }^{c}$ Median EBV VCA IgA;

${ }^{d}$ Median EBV EA IgA;

${ }^{e}$ Median metastasis size.

in none of the patients, and all of them received external beam radiotherapy by a $6 \mathrm{MV}$ linear accelerator. All patients had planning computerized tomography of the head and neck performed with patient in the treatment 
position. Computerized tomography-assisted radiation treatment planning was obtained before the initiation of radiotherapy. A dose of 68-70 Gy/6.5-7 weeks was normally given to the primary tumor. A does of 64-66 Gy/6-7 weeks to the involved neck nodes, whereas the does for node-negative neck was 50 Gy/5-5.5 weeks. Therapeutic efficacy was assessed 3-6 months after the primary treatment, according to the Response Evaluation Criteria in Solid Tumors (RECIST) criteria.

The patients were followed up in the out-patient clinics, where diagnostic examinations consisting of nasopharyngeal and neck magnetic resonance imaging (MRI), chest $\mathrm{x}$-ray and/or CT, abdominal ultrasonography and bone scan were performed every 3-6 months for the first 3 years and finally annually thereafter to detect local recurrence and/or metastasis. For those present with lung metastasis (es) alone as the first failure, 4-6 cycles of palliative chemotherapy with DDP based regimen was administered. Local therapies such as surgery or radiotherapy served as options for those still with metastatic lesions limited in lung after chemotherapy.

\section{Statistical analysis}

Statistical analysis was performed using SPSS 13.0 package (SPSS Standard version 13.0, SPSS Inc, Chicago, IL). Chi-square test was used to compare the difference of categorical variables. Disease-free interval (DFI) was calculated from the completion of initial treatment to the time when lung metastasis(es) was identified. Overall survival (OS) or post-metastasis survival (PMS) was defined as from the date of completing the initial treatment or the date of lung metastasis(es) identified to the date of death or the last follow-up, respectively. The survival curves were calculated by the Kaplan-Meier method and compared using the log-rank test. Multivariate survival analysis was performed on all parameters that were found significant on univariate analysis using the Cox regression model. $P$ values $<0.05$ were considered significant.

\section{Results}

Patients' characteristics and treatments

The clinical and pathological characteristics of the 246 NPC patients with lung metastasis(es) alone in this study are listed in Table 1. Among 246 patients, 45 patients were diagnosed with NPC along with lung metastasis(es) while the other 201 cases developed lung metastasis(es) after primary treatment. Single radiotherapy, concurrent chemoradiotherapy and 6 cycles of chemotherapy followed by concurrent chemoradiotherapy were performed in 55, 146 and 45 cases, respectively. Each of the patients had a complete remission (CR) for nasopharynx and the involved cervical nodes after the primary treatment.
After the lung metastasis(es), all the patients received at least 4-6 cycles of chemotherapy, 126 cases of which received $\leq 6$ cycles, the other 120 cases received $>6$ cycles. CR for the metastatic lung lesions evaluated by CT was obtained in $4.9 \%(12 / 246)$ of the patients after chemotherapy; for those CR was not obtained, palliative metastasectomy or radiotherapy was served as an option, and was performed in 27 and 37 of the 234 patients. Local-regional recurrence along with or after lung metastasis(es) was observed in 31 patients out of the total 246 cases. The 23 cases with local nasopharyngeal recurrence had palliative radiotherapy and the other 8 cases with regional lymph nodes recurrence received regional neck lymph nodes dissection.

The treatment of lung metastasis(es) and/or local recurrence were tolerated. The Common Terminology Criteria for Adverse Events (CTCAE) was used to evaluate the acute toxicity. There were no treatmentrelated deaths and no grade 4 toxicity. The acute toxicities were listed in Table 2. Twelve patients experienced long-term toxicities such as xerostomia (six patients), mucositis (three patients), radiation pneumonitis (two patients) and sensorineural hearing loss (one patient).

Table 2 Grade 3/4 acute toxicity according to CTCAE.

\begin{tabular}{|c|c|c|}
\hline Acute toxicity & No. of patients & $\%$ \\
\hline Evaluable patients & 198 & \\
\hline \multicolumn{3}{|l|}{ Leukopenia } \\
\hline Grade 3 & 65 & 32.8 \\
\hline Grade 4 & 0 & 0 \\
\hline \multicolumn{3}{|l|}{ Thrombocytopenia } \\
\hline Grade 3 & 19 & 9.6 \\
\hline Grade 4 & 0 & 0 \\
\hline \multicolumn{3}{|l|}{ Anemia } \\
\hline Grade 3 & 30 & 15.2 \\
\hline Grade 4 & 0 & 0 \\
\hline \multicolumn{3}{|l|}{ Vomitting } \\
\hline Grade 3 & 22 & 11.1 \\
\hline Grade 4 & 0 & 0 \\
\hline \multicolumn{3}{|l|}{ Mucositis } \\
\hline Grade 3 & 25 & 12.6 \\
\hline Grade 4 & 0 & 0 \\
\hline \multicolumn{3}{|l|}{ Diarrhea } \\
\hline Grade 3 & 6 & 3.0 \\
\hline Grade 4 & 0 & 0 \\
\hline \multicolumn{3}{|l|}{ Stomatitis } \\
\hline Grade 3 & 6 & 3.0 \\
\hline Grade 4 & 0 & 0 \\
\hline \multicolumn{3}{|l|}{ Renal toxicity } \\
\hline Grade 3 & 0 & 0 \\
\hline Grade 4 & 0 & 0 \\
\hline
\end{tabular}

Abbreviation: CTCAE, Common Terminology Criteria for Adverse Events. 


\section{Association between clinical characteristics and DFI}

The mean and median DFI for the primary M0 cases were 34.4 months and 22.7 months, respectively, ranging from 2.3 months to 184.9 months. The mean and median DFI for the primary M1 cases were calculated as 0. In total, there are 92, 86, and 68 cases with a DFI less than 1 year, 1-3 years and greater than 3 years, respectively. As shown in Table 3, patients with age less than 45 years, T1-2 and N0 classification seems to have a longer DFI before lung metastasis(es) developed than those with age greater than 45 years, T3-4 and N1-3 classification.

\section{Survival status}

The median observation period was 45.8 months (range, 3.2-218.7 months) for the whole cohort, and 170 deaths were observed. The 3-year, 5-year and 10-year OS and PMS for the entire cohort of patients were $67.8 \%, 45.4 \%$, $18.5 \%$ and $34.3 \%, 17.0 \%, 8.6 \%$, respectively (Figure $1 \mathrm{~A}$ and $1 \mathrm{~B})$. The median survival time of patients with M0 classification compared with M1 classification was significantly longer in OS (61.7 months vs. 26.8 months, $P<0.001)$ but similar in PMS (26.2 months vs. 26.8 months, $P=0.758$, Figure $1 \mathrm{C}$ and $1 \mathrm{D})$. The median OS and PMS for patients

Table 3 Association between clinical characteristics and DFI in 246 NPC patients with lung metastasis(es) alone at diagnosis or the first failure

\begin{tabular}{|c|c|c|c|c|}
\hline \multirow[b]{2}{*}{ Characteristics } & \multicolumn{4}{|c|}{ Disease-free interval } \\
\hline & $\leq 1$ year & 1-3 years & $\geq 3$ years & $P^{a}$ \\
\hline Age (years) & & & & 0.018 \\
\hline$\leq 45$ & $39(30.0)$ & $47(36.2)$ & $44(33.8)$ & \\
\hline$>45$ & $53(45.7)$ & 39 (33.6) & $24(20.7)$ & \\
\hline Gender & & & & 0.701 \\
\hline Male & $75(38.3)$ & $66(33.6)$ & $55(28.1)$ & \\
\hline Female & $17(34.0)$ & $20(40.0)$ & $13(26.0)$ & \\
\hline EBV VCA-lgA $A^{b}$ & & & & 0.624 \\
\hline$\leq 320: 1^{c}$ & $35(35.0)$ & $37(37.0)$ & $28(28.0)$ & \\
\hline$>320: 1$ & $30(42.9)$ & $22(31.4)$ & $18(25.7)$ & \\
\hline$E B V E A-\lg A^{b}$ & & & & 0.826 \\
\hline$\leq 40: 1^{d}$ & $42(37.5)$ & $38(33.9)$ & $32(28.6)$ & \\
\hline$>40: 1$ & $23(39.7)$ & $21(36.2)$ & $14(24.1)$ & \\
\hline UICC T classification & & & & 0.001 \\
\hline $\mathrm{T} 1-2$ & $25(25.8)$ & $33(34.0)$ & $39(40.2)$ & \\
\hline $\mathrm{T} 3-4$ & $67(45.0)$ & $53(35.5)$ & $29(19.5)$ & \\
\hline UICC N classification & & & & 0.012 \\
\hline NO & $10(24.4)$ & $12(29.3)$ & $19(46.3)$ & \\
\hline N1-3 & $82(40.0)$ & $74(36.1)$ & 49 (23.9) & \\
\hline
\end{tabular}

Abbreviation: NPC, nasopharyngeal carcinoma; DFI, disease-free interval; UICC, International Union Against Cancer.

${ }^{a}$ Chi-square test;

${ }^{b}$ Data was available for 170 cases;

c Median EBV VCA IgA;

${ }^{d}$ Median EBV EA IgA. treated with combined therapy and chemotherapy alone were 73.7 months, 46.2 months $(P<0.001)$ and 45.6 months, 23.7 months $(P<0.001)$, respectively (Figure $1 \mathrm{E}$ and $1 \mathrm{~F})$.

\section{Prognostic factors of survival}

In univariate analysis, age, EBV VCA-lgA, DFI, metastasis site, metastasis number, local-regional recurrence, treatment modality and chemotherapy effect were evaluated as predicting factors for PMS; while only age and treatment modality retained their significance in multivariate analysis (Table 4). Similarly, age, T classification, N classification, M classification, DFI, metastasis site, metastasis number, metastasis size and treatment modality were evaluated as prognostic factors for OS; while only age, DFI and treatment modality retained their significance in multivariate analysis (Table 4).

Since age and DFI together with treatment modality were found to be important prognostic factors for patient survival, we next performed stratified analysis according to age and DFI to find out which subgroups of NPC patients with lung metastasis(es) alone will benefit from the combined therapy modality. The results showed that patients treated with combined therapy presented a better survival than those treated only with chemotherapy in both age less than 45 years and age greater than 45 years subgroups (Table 5). Treatment modality could also stratify the outcome of patients with DFI greater than 1 year, but not those with DFI less than 1 year (Table 5, Figure 2).

\section{Discussion}

Although the prognosis of metastatic NPC is still quite poor, it has been well accepted that the survival of metastatic NPC can be highly variable and long-term survival is possible in some patients [7-9,17,23,24]. Particularly, NPC patients with lung metastasis(es) alone were reported as a distinctive group with a good prognosis compared with other type of metastasis $[7,8]$. Thus, the identification of prognostic factors of this group will be of great importance from both a therapeutic and research point of view. In this study, we presented the long-term outcome and prognostic indicators of survival in a large cohort of NPC patients with lung metastasis(es) alone.

The 3-year OS and PMS reported in metastatic NPC patients with different series were less than $40 \%$ and $20 \%$, respectively [9]. In the present study, we reported a much better prognosis in 246 NPC patients with lung metastasis (es) alone, with a 3-year OS of $67.8 \%$ and a 3-year PMS of $34.3 \%$. Our results concurred closely with another study of lung metastasis of NPC in Hong Kong that NPC patients with lung metastasis(es) alone $(n=41)$ appeared to have a distinctively better prognosis, with a hazards ratio (HR) of 0.41 compared with other types of metastasis(es) [7]. In other studies, intrathoracic metastasis(es) (lung and/or 

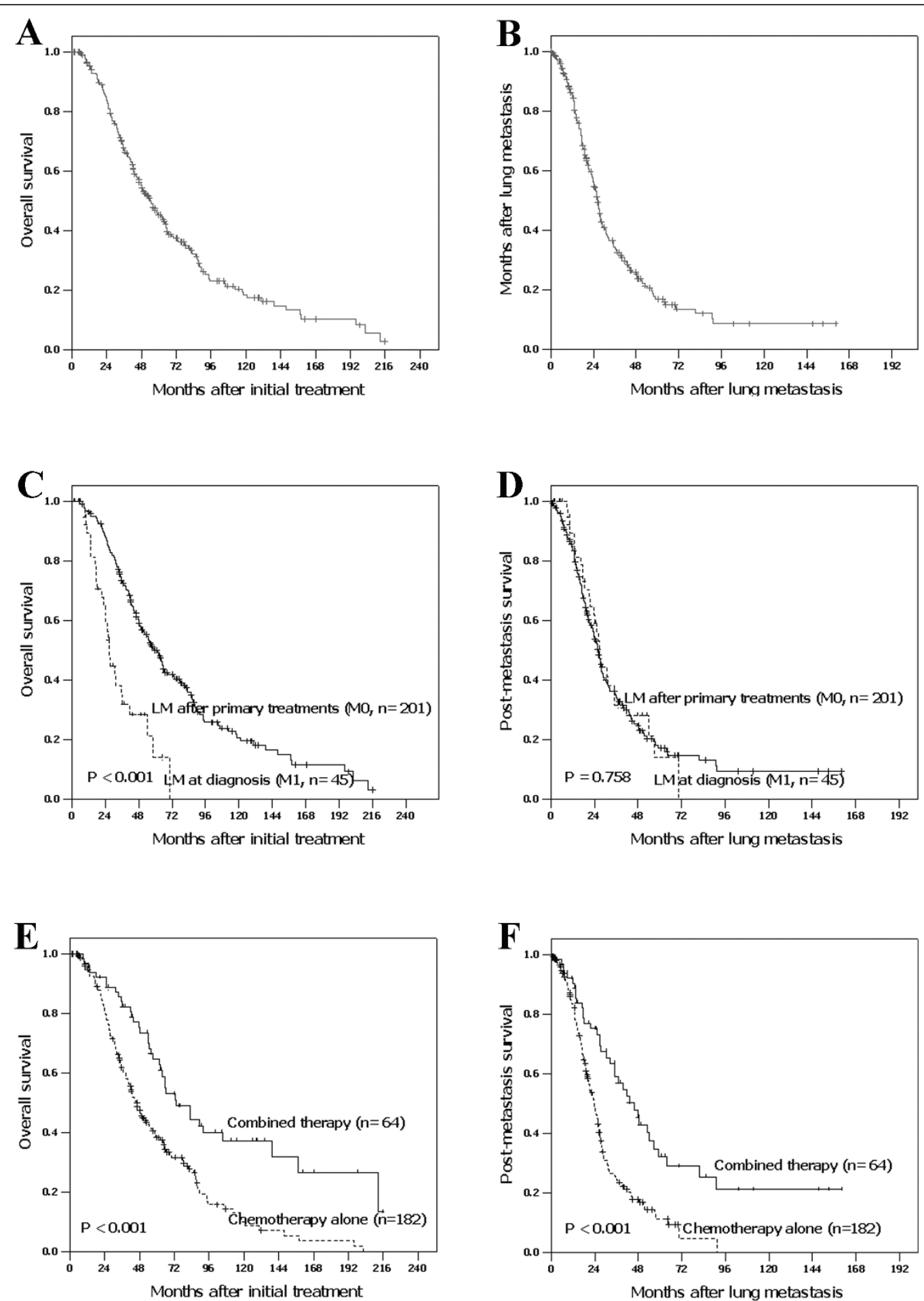

Figure 1 Survival analysis according to different groups. Overall survival (OS) and post-metastasis survival (PMS) curves for the whole cohort $(A$ and $B$ ) and stratified by M classification ( $C$ and $D)$ and treatment modalities ( $E$ and $F$ ).

mediastinal nodes) was considered as a good prognostic factor in metastatic NPC $[8,20,21]$. However, to our knowledge, no literature has identified the precise predictive factors for the prognosis in this specific group.
It was demonstrated in our study that young age $(\leq 45$ years), long DFI (> 1 year), unilateral metastasis, solitary metastasis and combined therapy were good prognostic factors in terms of both OS and PMS based on 
Table 4 Prognostic variables of 246 NPC patients with lung metastasis(es) alone at diagnosis or the first failure

\begin{tabular}{|c|c|c|c|c|c|c|c|c|}
\hline \multirow[b]{2}{*}{ Variables } & \multicolumn{3}{|c|}{ Post-metastasis survival } & \multirow[b]{2}{*}{$P^{a}$} & \multicolumn{4}{|c|}{ Overall survivall } \\
\hline & Univariate Analysis & $P^{a}$ & Multivariate Analysis & & Univariate Analysis & $P^{a}$ & Multivariate Analysis & $P^{a}$ \\
\hline$\overline{\text { Age }}$ & $1.485(1.097-2.010)$ & 0.010 & $1.537(1.038-2.277)$ & 0.032 & $1.734(1.277-2.355)$ & $<0.001$ & $1.424(1.027-1.974)$ & 0.034 \\
\hline Sex & $1.018(0.712-1.458)$ & 0.921 & - & - & $1.022(0.714-1.463)$ & 0.905 & - & - \\
\hline T classification & $1.298(0.948-1.778)$ & 0.104 & - & - & $1.774(1.281-2.456)$ & 0.001 & $1.326(0.936-1.876)$ & 0.112 \\
\hline N classification & $1.224(0.809-1.852)$ & 0.339 & - & - & $1.758(1.150-2.688)$ & 0.009 & $1.395(0.905-2.150)$ & 0.131 \\
\hline M classification & $0.938(0.625-1.408)$ & 0.758 & - & - & $3.010(1.965-4.612)$ & $<0.001$ & $1.290(0.766-2.172)$ & 0.338 \\
\hline EBV VCA-lgA & $1.490(1.033-2.148)$ & 0.033 & $1.342(0.920-1.958)$ & 0.127 & $1.348(0.935-1.942)$ & 0.110 & - & - \\
\hline EBV EA-lgA & $1.171(0.803-1.710)$ & 0.412 & - & - & $1.199(0.820-1.753)$ & 0.349 & - & - \\
\hline DFI & $0.818(0.676-0.991)$ & 0.040 & $1.019(0.796-1.304)$ & 0.881 & $0.326(0.263-0.404)$ & $<0.001$ & $0.379(0.294-0.490)$ & $<0.001$ \\
\hline Metastasis site & $1.846(1.357-2.512)$ & $<0.001$ & $1.295(0.779-2.153)$ & 0.319 & $1.964(1.439-2.682)$ & $<0.001$ & $1.561(0.967-2.520)$ & 0.068 \\
\hline Metastasis number & $1.813(1.295-2.539)$ & 0.001 & $1.274(0.705-2.301)$ & 0.422 & $1.970(1.403-2.768)$ & $<0.001$ & $1.284(0.761-2.097)$ & 0.365 \\
\hline Metastasis size & $0.952(0.699-1.296)$ & 0.754 & - & - & $0.689(0.505-0.941)$ & 0.019 & $0.922(0.664-1.281)$ & 0.629 \\
\hline Recurrence & $1.785(1.125-2.832)$ & 0.014 & $1.429(0.778-2.625)$ & 0.250 & $1.197(0.755-1.896)$ & 0.444 & - & - \\
\hline Treatment modality ${ }^{\mathrm{b}}$ & $0.440(0.302-0.641)$ & $<0.001$ & $0.583(0.355-0.960)$ & 0.034 & $0.454(0.321-0.660)$ & $<0.001$ & $0.566(0.374-0.857)$ & 0.007 \\
\hline Chemotherapy cycle $^{c}$ & $0.828(0.612-1.122)$ & 0.828 & - & & $1.143(0.842-1.552)$ & 0.392 & - & - \\
\hline -Chemotherapy effect ${ }^{d}$ & $2.305(1.016-5.228)$ & 0.046 & $1.243(0.511-3.026)$ & 0.632 & $1.603(0.708-3.627)$ & 0.258 & - & - \\
\hline
\end{tabular}

Abbreviation: NPC, nasopharyngeal carcinoma; DFI, disease-free interval.

${ }^{a}$ Cox proportional hazards analysis.

${ }^{b}$ Chemotherapy alone vs. combined therapy;

c chemotherapy cycle $<6$ vs. chemotherapy cycle $\geq 6$;

${ }^{d}$ Complete remission vs. non-complete remission. 
Table 5 Stratified analysis in 246 NPC patients with lung metastasis(es) alone at diagnosis or the first failure

\begin{tabular}{|c|c|c|c|c|c|}
\hline \multirow[b]{2}{*}{ Variables } & \multirow[b]{2}{*}{ Cases } & \multicolumn{2}{|l|}{ PMS } & \\
\hline & & HR (95\% Cl) & $P^{a}$ & HR $(95 \% \mathrm{Cl})$ & $P^{a}$ \\
\hline Age $\leq 45$ years & & & 0.004 & & 0.005 \\
\hline Chemo alone & 90 & 1 & & 1 & \\
\hline Chemo+local & 40 & $0.484(0.293-0.798)$ & & $0.485(0.292-0.805)$ & \\
\hline Age $>45$ years & & & 0.005 & & 0.006 \\
\hline Chemo alone & 92 & 1 & & 1 & \\
\hline Chemo+local & 24 & $0.434(0.242-0.779)$ & & $0.451(0.257-0.792)$ & \\
\hline $\mathrm{DFI}<1$ year & & & 0.283 & & 0.571 \\
\hline Chemo alone & 78 & 1 & & 1 & \\
\hline Chemo+local & 14 & $0.676(0.332-1.380)$ & & $0.814(0.400-1.656)$ & \\
\hline $\mathrm{DFI}=1 \sim 3$ years & & & 0.008 & & 0.005 \\
\hline Chemo alone & 59 & 1 & & 1 & \\
\hline Chemo+local & 27 & $0.460(0.260-0.815)$ & & $0.429(0.239-0.770)$ & \\
\hline $\mathrm{DFI}>3$ years & & & 0.006 & & 0.006 \\
\hline Chemo alone & 45 & 1 & & 1 & \\
\hline Chemo+local & 23 & $0.353(0.168-0.739)$ & & $0.342(0.160-0.730)$ & \\
\hline
\end{tabular}

Abbreviation: NPC, nasopharyngeal carcinoma; PMS, post-metastasis survival; OS, overall survival; $\mathrm{HR}$, hazard ratio; $95 \% \mathrm{Cl}$, 95\% confidence interval; DFI, diseasefree interval.

${ }^{a}$ Cox proportional hazards analysis.

univariate survival analysis, while only young age, long DFI and combined therapy were found to be independent good prognostic factors of OS according to multivariate analysis. These factors have also been indicated in other studies as good prognosis in patients with lung metastasis(es) from head and neck cancers $[4,11,25,26]$. For young age, we cannot explain clearly why it is a good prognostic factor, but it may be related to the significant association between young age and long DFI found in the present study. In another hand, young patients usually have better performance status to tolerate the side effect of aggressive combined therapy, and react positively towards the treatment than old patients, and thus they are more likely to accept the treatment after the discovery of lung metastasis(es) than elderly patients.

DFI has long been identified as an important prognostic factor for patient outcome, but the significant cutoff points of DFI are still uncertain according to the literatures [4,8,11,27-29]. In NPC, Teo et al reported that the OS of patients presenting with distant metastasis(es) abinitio $(M 1, D F I=0)$ is much worse than those developing distant metastasis(es) after primary radiotherapy $(\mathrm{M} 0, \mathrm{DFI}>0)[8]$. In our study, DFI $=0(\mathrm{M} 1)$ was also found to a poor prognostic factor of OS of NPC patients in univariate analysis, but there was no difference of PMS between DFI $=0$ months $($ M1) and DFI $>0$ months (M0) groups. Another reported cutoff of DFI < 6 months, which was identified by Ong et al as an independent prognostic factor of PMS in metastatic NPC; while in another study conducted by Khanfir et al, no difference of PMS between groups with DFI $\leq 6$ months and DFI $>6$ months was observed $[4,11]$. It's believed that different types of metastatic NPC might correspond with different significant cutoff points of DFI, which might partly contribute the variances of DFI cutoff points reported in the literatures. In our study, we proposed that DFI $\leq 1$ year, $1-3$ years and $>3$ years were the proper cutoff values to distinguish both the OS and PMS in NPC patients with lung metastasis(es) alone. Patients with young age ( $\leq 45$ years), early $\mathrm{T}$ classification, and without lymph node metastasis would be likely to have longer DFI.

Treatment modality is another important independent prognostic factor in our study. We demonstrated that, compared to single chemotherapy, combined therapy improved both the OS and PMS for NPC patients with lung metastasis(es) alone. Geara et al reported similar results in 103 metastatic NPC patients who treated with radiotherapy and chemotherapy (2 yeras-OS, $45 \%$ ) for their metastases had a significantly better survival than those received no treatment (2 years-OS, 14\%) or single chemotherapy (2 years-OS, $18 \%, P=0.001$ ) [22]. In addition, some long-term survivors aggressively treated with pulmonary metastasectomy in combination with chemotherapy were also reported in NPC patients with intrathoracic metastasis(es) alone [10,12,13,20,28-30]. Collectively, these data suggests an indication for combined therapy in selected metastatic NPC patients. Thus, it seems necessary to further evaluate which subgroup of patients would benefit from it. In our stratified survival analysis, treatment modality was found to have improved the outcome of patients with DFI greater than 1 year, but not those with DFI less than 1 year. 

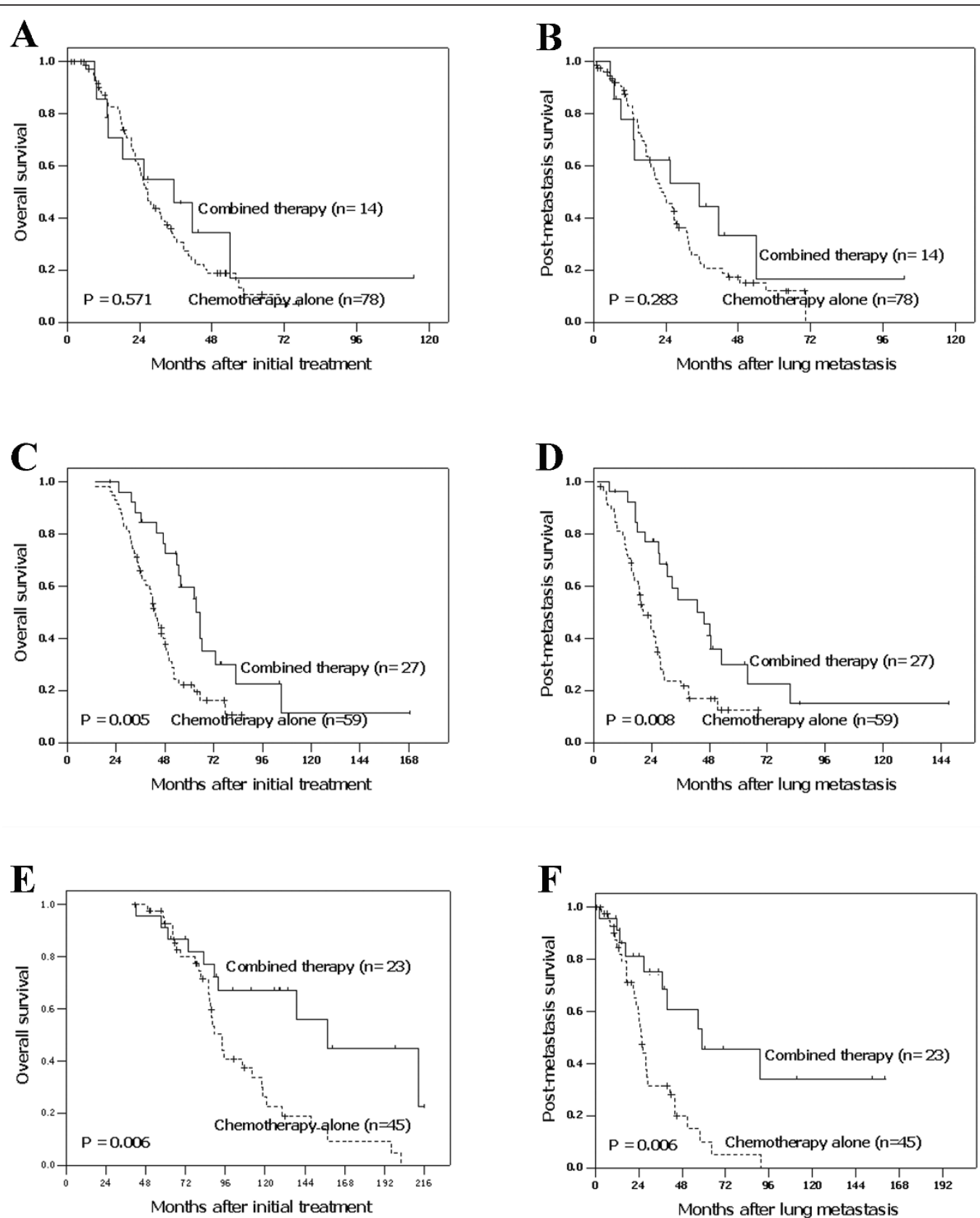

Figure 2 Stratified analysis according to age, DFI and treatment modality. Overall survival (OS) and post-metastasis survival (PMS) curves stratified by treatment modalities in different disease-free intervals (DFI): DFI < 1 year ( $A$ and $B$ ), DFI = 1-3 years (C and D) and DFI > 3 years (E and F).

There are several limitations to our study. Our study is a retrospective study, relied exclusively on a singleinstitutional database. A larger scale, prospective, multicenter study is needed to confirm our results.

\section{Conclusions}

In conclusion, our study is the first retrospective study in southern China to identify the prognostic indicators of long-term survival in a large group of NPC patients with lung metastasis(es) alone. Based on our results, age less than 45 years, DFI greater than 1 year and the combined modality treatment were good prognostic factors. The combined therapy should be highly considered for lung metastatic NPC patient with DFI greater than 1 year to achieve better survival.

\section{Acknowledgements}

This study was supported by grants from the Science and Technology Project of Guangzhou, China (2009Y-C011-2). 


\section{Author details}

${ }^{1}$ State Key Laboratory of Oncology in South China, Cancer Center, Sun YatSen University, Guangzhou, China. ${ }^{2}$ Department of Thoracic Oncology, Cancer Center, Sun Yat-Sen University, No.651, Dongfeng Road East, Guangzhou, China. ${ }^{3}$ Department of Radiation Oncology, Cancer Center, Sun Yat-Sen University, No.651, Dongfeng Road East, Guangzhou, China.

\section{Authors' contributions}

XC performed the statistical analysis, drafted the manuscript and participated in the sequence alignment. LRH participated in the design of the study and participated in the sequence alignment. FYX participated in the sequence alignment. YFC carried out data acquisition. ZSW conceived of the study, and participated in its design and coordination and helped to draft the manuscript. All authors read and approved the final manuscript.

\section{Competing interests}

The authors declare that they have no competing interests.

Received: 12 April 2011 Accepted: 24 August 2011

Published: 24 August 2011

\section{References}

1. Jemal A, Bray F, Center MM, Ferlay J, Ward E, Forman D: Global cancer statistics. CA Cancer J Clin 2011, 61:69-90.

2. Razak AR, Siu LL, Liu FF, Ito E, O'Sullivan B, Chan K: Nasopharyngeal carcinoma: the next challenges. Eur J Cancer 2010, 46:1967-1978.

3. Wei WI, Sham JS: Nasopharyngeal carcinoma. Lancet 2005, 365:2041-2054.

4. Khanfir A, Frikha M, Ghorbel A, Drira MM, Daoud J: Prognostic factors in metastatic nasopharyngeal carcinoma. Cancer Radiother 2007, 11:461-464.

5. Leibel SA, Scott CB, Mohiuddin M, Marcial VA, Coia LR, Davis LW, Fuks Z: The effect of local-regional control on distant metastatic dissemination in carcinoma of the head and neck: results of an analysis from the RTOG head and neck database. Int J Radiat Oncol Biol Phys 1991, 21:549-556.

6. Ng WT, Lee MC, Hung WM, Choi CW, Lee KC, Chan OS, Lee AW: Clinical outcomes and patterns of failure after intensity-modulated radiotherapy for nasopharyngeal carcinoma. Int J Radiat Oncol Biol Phys 2011, 79:420-428.

7. Hui EP, Leung SF, Au JS, Zee B, Tung S, Chua D, Sze WM, Law CK, Leung TW, Chan AT: Lung metastasis alone in nasopharyngeal carcinoma: a relatively favorable prognostic group. A study by the Hong Kong Nasopharyngeal Carcinoma Study Group. Cancer 2004, 101:300-306.

8. Teo PM, Kwan WH, Lee WY, Leung SF, Johnson PJ: Prognosticators determining survival subsequent to distant metastasis from nasopharyngeal carcinoma. Cancer 1996, 77:2423-2431.

9. Khanfir A, Frikha M, Ghorbel A, Karray H, Drira MM, Daoud J: Metastatic nasopharyngeal carcinoma: clinical study and therapeutic results of 95 cases. Cancer Radiother 2006, 10:545-549.

10. Winter H, Meimarakis G, Hoffmann G, Hummel M, Ruttinger D, Zilbauer A, Stelter K, Spelsberg F, Jauch KW, Hatz R, Lohe F: Does surgical resection of pulmonary metastases of head and neck cancer improve survival? Ann Surg Oncol 2008, 15:2915-2926.

11. Ong YK, Heng DM, Chung B, Leong SS, Wee J, Fong KW, Tan T, Tan EH: Design of a prognostic index score for metastatic nasopharyngeal carcinoma. Eur J Cancer 2003, 39:1535-1541.

12. Haro A, Yano T, Yoshida T, Ito K, Morodomi Y, Shoji F, Nakashima T, Maehara Y: Results of a surgical resection of pulmonary metastasis from malignant head and neck tumor. Interact Cardiovasc Thorac Surg 2010, 10:700-703.

13. Younes RN, Gross JL, Silva JF, Fernandez JA, Kowalski LP: Surgical treatment of lung metastases of head and neck tumors. Am J Surg 1997, 174:499-502.

14. Leong SS, Wee J, Rajan S, Toh CK, Lim WT, Hee SW, Tay MH, Poon D, Tan EH: Triplet combination of gemcitabine, paclitaxel, and carboplatin followed by maintenance 5 -fluorouracil and folinic acid in patients with metastatic nasopharyngeal carcinoma. Cancer 2008, 113:1332-1337.

15. Wee J, Tan EH, Tai BC, Wong HB, Leong SS, Tan T, Chua ET, Yang E, Lee KM, Fong KW, et al: Randomized trial of radiotherapy versus concurrent chemoradiotherapy followed by adjuvant chemotherapy in patients with American Joint Committee on Cancer/International Union against cancer stage III and IV nasopharyngeal cancer of the endemic variety. J Clin Oncol 2005, 23:6730-6738.
16. Chan AT, Hsu MM, Goh BC, Hui EP, Liu TW, Millward MJ, Hong RL, WhangPeng J, Ma BB, To KF, et al: Multicenter, phase II study of cetuximab in combination with carboplatin in patients with recurrent or metastatic nasopharyngeal carcinoma. J Clin Oncol 2005, 23:3568-3576.

17. Fandi A, Bachouchi M, Azli N, Taamma A, Boussen H, Wibault $P$, Eschwege F, Armand JP, Simon J, Cvitkovic E: Long-term disease-free survivors in metastatic undifferentiated carcinoma of nasopharyngeal type. J Clin Oncol 2000, 18:1324-1330.

18. Chua DT, Sham JS, Au GK: A phase II study of capecitabine in patients with recurrent and metastatic nasopharyngeal carcinoma pretreated with platinum-based chemotherapy. Oral Oncol 2003, 39:361-366.

19. Ngan RK, Yiu HH, Lau WH, Yau S, Cheung FY, Chan TM, Kwok CH, Chiu CY, Au SK, Foo W, et al: Combination gemcitabine and cisplatin chemotherapy for metastatic or recurrent nasopharyngeal carcinoma: report of a phase II study. Ann Oncol 2002, 13:1252-1258.

20. Cheng LC, Sham JS, Chiu CS, Fu KH, Lee JW, Mok CK: Surgical resection of pulmonary metastases from nasopharyngeal carcinoma. Aust N $Z$ J Surg $1996,66: 71-73$

21. Kwan WH, Teo PM, Chow LT, Choi PH, Johnson PJ: Nasopharyngeal carcinoma with metastatic disease to mediastinal and hilar lymph nodes: an indication for more aggressive treatment. Clin Oncol (R Coll Radiol) 1996, 8:55-58.

22. Geara FB, Sanguineti G, Tucker SL, Garden AS, Ang KK, Morrison WH, Peters L: Carcinoma of the nasopharynx treated by radiotherapy alone: determinants of distant metastasis and survival. Radiother Oncol 1997, 43:53-61.

23. Wolff HA, Rodel RM, Gunawan B, Overbeck T, Herrmann MK, Hennies S, Hille A, Vorwerk H, Matthias C, Hess CF, Christiansen H: Nasopharyngeal carcinoma in adults: treatment results after long-term follow-up with special reference to adjuvant interferon-beta in undifferentiated carcinomas. J Cancer Res Clin Oncol 2010, 136:89-97.

24. Gokce T, Unlu I, Akcay C: Evaluation of overall survival of nasopharyngeal carcinoma patients treated in ten years at a single institution. Journal of Buon 2010, 15:36-42.

25. Wang CT, Cao KJ, Li Y, Xie GF, Huang PY: Prognosis analysis of nasopharyngeal carcinoma patients with distant metastasis. Ai Zheng 2007, 26:212-215.

26. Fang FM, Tsai WL, Chien CY, Chen HC, Hsu HC, Huang TL, Lee TF, Huang $\mathrm{HY}$, Lee $\mathrm{CH}$ : Pretreatment quality of life as a predictor of distant metastasis and survival for patients with nasopharyngeal carcinoma. J Clin Oncol 2010, 28:4384-4389.

27. Shiono S, Kawamura M, Sato T, Nakagawa K, Nakajima J, Yoshino I, Ikeda N, Horio H, Akiyama H, Kobayashi K: Disease-free interval length correlates to prognosis of patients who underwent metastasectomy for esophageal lung metastases. I Thorac Oncol 2008, 3:1046-1049.

28. Chen F, Sonobe M, Sato K, Fujinaga T, Shoji T, Sakai H, Miyahara R, Bando T, Okubo K, Hirata T, Date H: Pulmonary resection for metastatic head and neck cancer. World I Surg 2008, 32:1657-1662.

29. Shiono S, Kawamura M, Sato T, Okumura S, Nakajima J, Yoshino I, Ikeda N, Horio H, Akiyama H, Kobayashi K: Pulmonary metastasectomy for pulmonary metastases of head and neck squamous cell carcinomas. Ann Thorac Surg 2009, 88:856-860.

30. Ma J, Wen $Z S$, Lin $P$, Wang $X$, Xie FY: The results and prognosis of different treatment modalities for solitary metastatic lung tumor from nasopharyngeal carcinoma: a retrospective study of 105 cases. Chin J Cancer 2010, 29:787-795.

\section{Pre-publication history}

The pre-publication history for this paper can be accessed here: http://www.biomedcentral.com/1471-2407/11/370/prepub

\section{doi:10.1186/1471-2407-11-370}

Cite this article as: Cao et al:: Factors determining the survival of nasopharyngeal carcinoma with lung metastasis alone: does combined modality treatment benefit? BMC Cancer 2011 11:370. 